\title{
REDDIT SENTIMENT ANALYSIS TO IMPROVE ELECTION PREDICTIONS
}

\author{
Bryant Hwang \\ Korea International School, South Korea
}

\begin{abstract}
Despite high rates of past success, the majority of polling agencies were unable to predict the outcome of the 2016 United States presidential election between Hillary Clinton and Donald Trump. Further research has hypothesized that these agencies underestimated the amount of support for Trump and overestimated the representation of recent college graduates. Sentiment analysis of posts on popular social media sites presents promising possibilities for better gauging public opinion. In our research, we analyze positive and negative sentiment in Reddit posts from key dates during the 2016 election that mention either candidate. The results of our study match the results of a poll conducted by the New York Times, which showed that public opinion for Trump tended to stay consistent while Clintons positive sentiment decreased over time. Our study also shows that public opinion expressed on Reddit changed drastically in accordance to major events, like debates and email controversies. Alone, our work in sentiment analysis does not produce statistically significant enough results to predict the final outcome of an election, but having the ability to gauge public opinion through social networks is a powerful way that polling agencies and researchers can strengthen their predictions in real time.
\end{abstract}

\section{KEYWORDS}

Sentiment Analysis, Election Prediction, Social Media, Reddit, Aylien

\section{INTRODUCTION}

Despite prior consistent success in predicting the outcomes of presidential elections, only fifteen out of 150 polls predicted Donald Trumps victory in the 2016 race (RealClearPolitics, 2019). This is a remarkable decrease from the $80 \%$ of pollsters that accurately predicted Barack Obamas victory against Mitt Romney in 2012 (RealClearPolitics, 2019). The American Association of Public Opinion Research conducted a study on this seemingly irrational result that narrowed down the the cause to three main reasons: the nonresponse bias, Shy Trumper hypothesis, and social desirability bias ("Election Polls in the U.S.").

The nonresponse bias is the idea that people continually refuse to respond to surveys, which caused pollsters to over- estimate the number of college graduate voters ("Election Polls in the U.S."). The Shy Trumper hypothesis states that Trump advocates hide their preference for Trump and is closely related to the social desirability bias, which is the idea that people vote for the candidate that is more favorably viewed by society ("Election Polls in the U.S."). Combined, the Shy Trumper hypothesis and the social desirability bias caused pollsters to underestimate the number of Trump supporters.

The presence of social media is quickly becoming influential in major elections. Both Barack Obama and Mitt Romney used social media sites like YouTube, Instagram, Facebook, Twitter, Tumblr, Pinterest, and Spotify to reach their younger constituents, but Obama had a much higher follower count: compare 18.5 million to 850 thousand followers (Pardee, 2019). More recently, Donald Trump used his Twitter feed to reach his 15.4 million followers.

In this study, we aim to evaluate the use of social media to predict the outcome of presidential elections. We use Google BigQuery and SQL to analyze sentiment on Reddit, a popular online forum. Reddit contains threads with diverse topics and is a far-reaching social media site, which gives us a variety and abundance of natural language data. 


\section{RELATED WORKS}

The relationship between the sentiment analysis of social media posts and the offline political landscape has been a controversial matter. A few political analysts claim that the Twittersphere shows political opinion to a certain extent, but others fear that the majority of comments on social media compose a pointless bubble. Tumasjan et al., however, have found that the frequency a political party is mentioned online has high correlation with the actual offline political landscape; most of the time, these numbers were found to be similar to the traditional election poll results and were sometimes found to have a higher correspondence to the true results than the traditional election polls.

Previous research done by Tumasjan et al. involved acquiring Tweets and checking if online Tweets mirrored offline political sentiment (2019). They used the Linguistic Inquiry and Word Count text analysis to determine if the sentiment of each message was positive, negative, or neutral towards a certain political party or politician. They concluded that Twitter was indeed used for political deliberation and reflected the offline political landscape.

We combine these two methods to analyze Reddit data: the volume of data and a sentiment analysis algorithm used by Gayo-Avello et al (2019).

\section{METHODOLOGY}

We analyze the frequency of certain occurrences and the sentiment of politically-related posts on Reddit, a popular internet forum. We use Reddit because it has high traffic and organizes its conversations by topic, which would give us a large amount of data about public opinion.

\subsection{Dataset}

We gather original posts (OPs) and responses to OPs that contain any combination of Donald, Trump, Hillary, or Clinton (case insensitive). We also restrict our data to a few key dates from the 2016 presidential election, presented in Table 1.

Table 1. Key Dates from The Presidential Election

\begin{tabular}{|c|c|}
\hline Date & Event \\
\hline July 18-21, 2016 & Republican National Convention \\
\hline July 25-28, 2016 & Democratic National Convention \\
\hline September 9, 2016 & Clinton calls Trump voters ignorant deplorables \\
\hline September 26, 2016 & First presidential debate \\
\hline October 7, 2016 & Trumps grab her by the pussy remarks surface \\
\hline October 9, 2016 & Second presidential debate \\
\hline October 28, 2016 & FBI reviewed new evidence Clinton emails \\
\hline November 7, 2016 & Day before the election \\
\hline
\end{tabular}

\subsection{Volume Analysis}

We first analyzed the Reddit traffic each candidate received and then compared it to the actual election. In a simple meta- analysis, we check if the number of times a candidate is mentioned online, without analyzing for sentiment, can predict the outcome of an election.

\subsection{Sentiment Analysis}

We use Aylien to classify each post as containing positive, negative, or neutral sentiment towards Clinton or Trump. We discard the neutral posts. The probability of candidate $\mathrm{c} 1$ winning the election is proposed to be 
where the positive/negative value of a candidate is the percent- age of data for that candidate with that sentiment multiplied by the number of Reddit posts that candidate has.

$$
p(c 1)=\frac{\operatorname{pos}(c 1)+\operatorname{neg}(c 1)}{\operatorname{pos}(c 1)+\operatorname{neg}(c 1)+\operatorname{pos}(c 2)+\operatorname{neg}(c 2)}
$$

\section{RESULTS AND DISCUSSION}

\subsection{Volume Analysis}

In the entire dataset we collected, Clinton and Trump were mentioned approximately equally as many times, with Trumps name being more frequent on July 18th-21st and October 7th and Clintons name being more frequent on September 9th and October 28th. These results, however, had a mean absolute error (MAE) of $18.5 \%$. With such a high MAE, we conclude that volume analysis alone is not enough to predict who will win the election and move on to sentiment analysis.

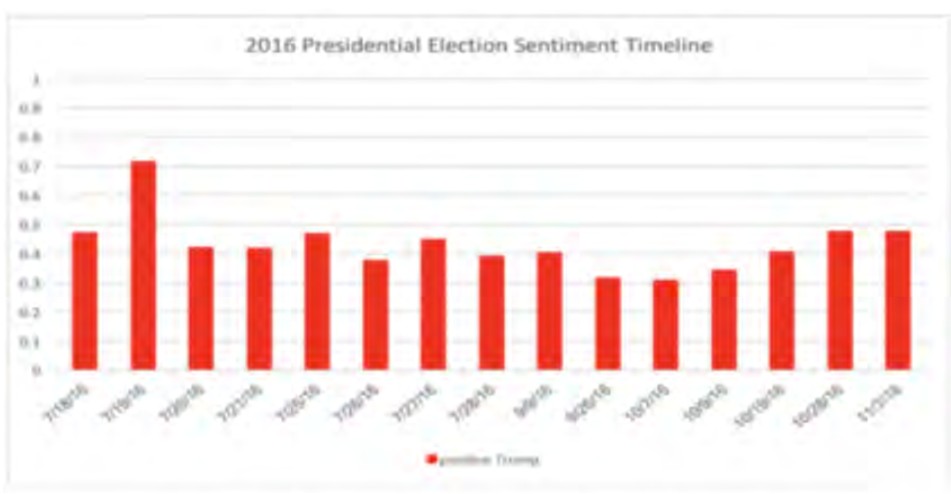

Figure 1. Positive Sentiment for Donald Trump

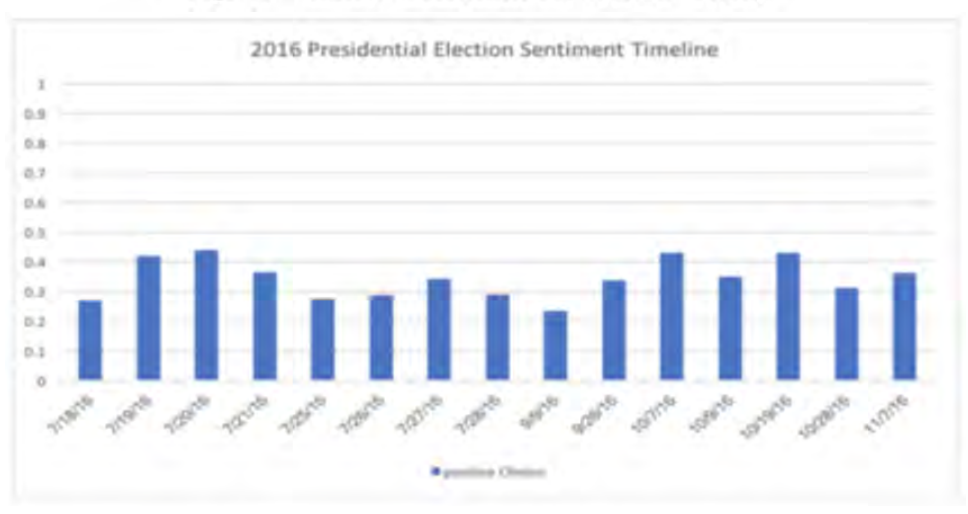

Figure 2. Positive Sentiment for Hillary Clinton

\subsection{Sentiment Analysis}

According to our data, the trend for people who positively viewed Trump was very consistent with only a few variances near the end of the campaigning period. However, the trend for people who positively viewed Clinton depreciated as time went by. We hypothesize that this is because of the email scandal that she suffered.

Figures 1 and 2 above show the positive sentiment for both candidates. The average positive sentiment was 42.8\% for Trump and 34.3\% for Clinton; interestingly, the majority of users seemed to dislike both candidates. 
The results in Figures 1 and 2 correlate with the results from a New York Times exit poll: 73\% of the people who voted for Trump believed that Clinton was neither honest nor trustworthy, and $71 \%$ of Clinton voters thought the same of Trump [25]. In the same study, when asked if Clinton was more qualified to serve as president, $89 \%$ of Trump voters responded that she was not, with similar results for Clinton voters [25].

The data from Reddit reflects a similar trend, showing that both candidates had mostly negative comments written about them. The graph presented in Figure 2 demonstrates that Trump had the least positive comments on October 7th, 2016, the same day that the video of Trump bragging about groping women surfaced on the internet. At this point of the presidential election, FiveThirtyEight gave Trump an $18.2 \%$ chance of winning the election. After this day, Trumps positive sentiment rises until election day.

In Figure 2, Clinton hits her lowest point in positive sentiment on September 9th, which was when Clinton called Trump supporters deplorables. On the other hand, her highest point was on July 20th, the day Trump was announced as the Republican candidate at the RNC, even though she had not been officially announced as the Democratic candidate yet. However, Clintons positive sentiment declined when the DNC chair Wasserman Schultz resigned after an email leak on July 25th; afterwards, Clinton was unable to achieve increasing or constant positive sentiment. In the end, she trailed behind Trump by $11.1 \%$ the day before the election.

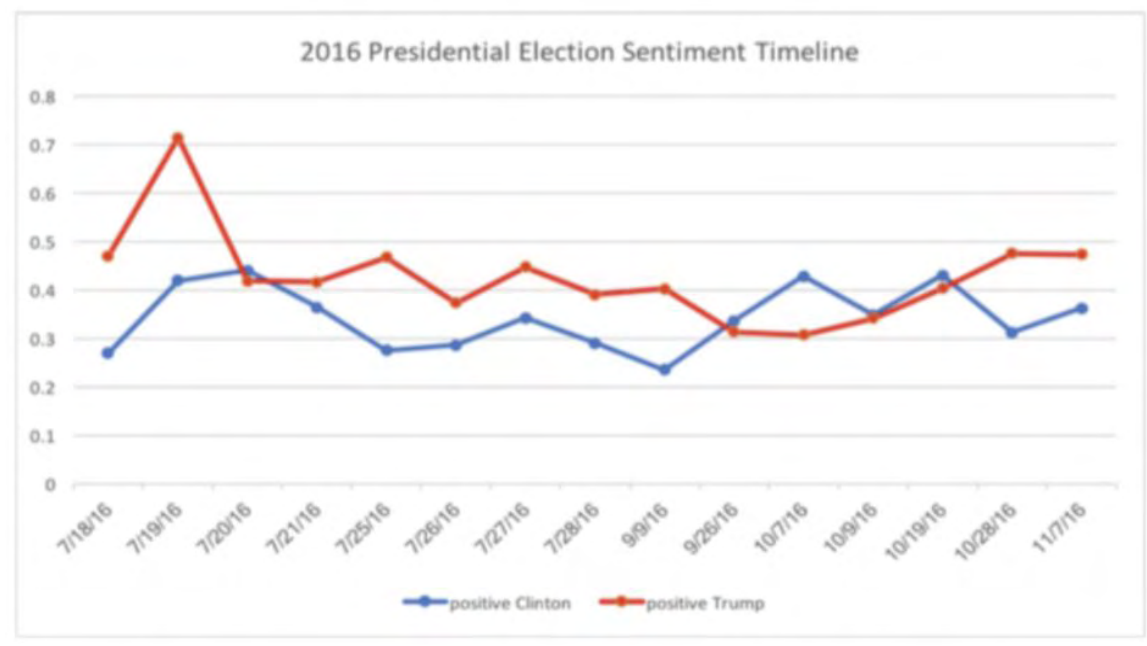

Figure 3. Combined Positive Sentiment for Both Candidates

\section{CONCLUSION}

Our research shows that the sentiment of relevant Reddit posts corresponded with results from election polls during the campaign season, which suggests that sentiment analysis is a viable avenue for predicting election results. We do, however, need to address some challenges if we are going to use sentiment analysis as a major tool for election prediction.

The first is that Reddit offers no location data, but location is an important part of the United States electoral college. Because the US does not elect presidents with the popular vote, who voted where matters. We also have no way of knowing if some geographical regions are overrepresented.

We also have to consider the prevalence of fake news, robots, and Russian interference. Fake accounts can corrupt data by misrepresenting the views of real people, and Russian interference, a heated topic during the election, can manipulate other people's thoughts. Russian interference was a significant problem for Twitter, which admitted that over 50,000 accounts were involved. Another source states that up to $45 \%$ of Trumps follower base could be made up of spam or fake accounts, which could have inflated his Reddit positive sentiment. Eliminating bias and filtering unwanted data is an important issue in sentiment analysis, but sentiment analysis is proving itself to be a successful way of gauging the publics view of presidential candidates. With improvement, sentiment analysis could be used during the election cycle to help understand how much the population likes a candidate, which seems to be the most important factor in winning an election. 


\section{REFERENCES}

Beaumont, A. (2019). US election final results: how Trump won. Retrieved from http://theconversation.com/us-electionfinal-results-how-trump-won-69356

Bort, J. (2019). Twitter Has a Big Problem with Fake User Accounts. Retrieved from https://www.businessinsider.com/twitter-has-a-big-problem-with-fake-user-accounts-2012-8

Ceron, A., Curini, L., \& Iacus, S. (2019). How pollsters could use social media data to improve election forecasts.

Retrieved from https://www.washingtonpost.com/news/monkey-cage/wp/2016/12/21/using-these-4-steps-pollsters-coulduse-social-media-data-to-improve-election-forecasts/?noredirect=on\&utm_term=.3a3779d0ed43

Evans, P. (2019). Can social media predict election results?. Retrieved from https://www.bbc.com/news/election-us-201637942842

Gayo-Avello, D., Metaxas, P., \& Mustafaraj, E. (2019). Limits of Electoral Predictions using Twitter. Proceedings of the Fifth International Conference On Weblogs and Social Media.

Goyder, J., Warriner, K., \& Miller, S. (2019). Evaluating Socioeconomic Status (SES) Bias in Survey Nonresponse. Journal of Official Statistics.

Hoffman, A. (2019). http://time.com. Retrieved from http://time.com/5268499/melania-trump-cyberbullying-humor/

Ingram, M. (2019). The Facebook Armageddon. Retrieved from https://www.cjr.org/special_report/facebook-mediabuzzfeed.php

Kennedy, C., Blumenthal, M., Clement, S., Clinton, J., Durand, C., \& Franklin, C. et al. (2019). An Evaluation of 2016 Election Polls in the U.S. - AAPOR. Retrieved from https://www.aapor.org/Education-Resources/Reports/AnEvaluation-of-2016-Election-Polls-in-the-U-S.aspx

Krombholz, K., Merkl, D., \& Weippl, E. (2012). Fake identities in social media: A case study on the sustainability of the Facebook business model. Journal Of Service Science Research, 4(2), 175-212. doi: 10.1007/s12927-012-0008-z

Matsa, K., \& Shearer, E. (2019). News Use Across Social Media Platforms 2018. Retrieved from https://www.journalism.org/2018/09/10/news-use-across-social-media-platforms-2018/

Mitchell, A., Holcomb, J., Barthel, M., \& Stocking, G. (2019). Reddit news users more likely to be male, young and digital in their news preferences. Retrieved from https://www.journalism.org/2016/02/25/reddit-news-users-more likely-tobe-male-young-and-digital-in-their-news-preferences/

The role of technology in the presidential election. (2019). Retrieved from https://www.economist.com/unitedstates/2016/11/20/the-role-of-technology-in-the-presidential-election

The role of technology in the presidential election. (2019). Retrieved from https://www.economist.com/unitedstates/2016/11/20/the-role-of-technology-in-the-presidential-election

Where polling failed, Facebook prevailed. (2019). Retrieved from https://www.economist.com/graphicdetail/2016/11/30/where-polling-failed-facebook-prevailed

Pardee, T. (2019). Infographic: How Obama, Romney (and Friends) Are Using Social Media. Retrieved from https://adage.com/article/campaign-trail/infographic-obama-romney-social-media/236798

Perez, S. (2019). Analysis of social media did a better job at predicting Trump's win than the polls -

TechCrunch. Retrieved from https://techcrunch.com/2016/11/10/social-media-did-a-better-job-at-predicting-trumps-winthan-the-polls/

RealClearPolitics - Election 2012 - General Election: Romney vs. Obama. (2019). Retrieved from https://www.realclearpolitics.com/epolls/2012/president/us/general_election_romney_vs_obama-1171.html

reddit.com Traffic Statistics. (2019). Retrieved from https://similarweb.com/website/reddit.com

Saru, N. (2019). What Is Twitter Doing about Fake News? - TechAcute. Retrieved from https://techacute.com/twitter-fakenews/

Syed, I. (2019). Retrieved from https://s3.amazonaws.com/app_usa_prod_eqffnyamdzrb/pdf6099\%20\%283\%29.pdf

Tumasjan, A., Sprenger, T., Sandner, P., \& Welpe, I. (2019). Predicting Elections with Twitter: What 140 Characters

Reveal about Political Sentiment. Proceedings Of The Fourth International Conference On Weblogs And Social Media.

Woolf, N. (2019). How to solve Facebook's fake news problem: experts pitch their ideas. Retrieved from https://www.theguardian.com/technology/2016/nov/29/facebook-fake-news-problem-experts-pitch-ideas-algorithms

Wortham, J. (2019). Presidential Campaign on Social Media. Retrieved from http://archive.nytimes.com/www.nytimes.com/interactive/2012/10/08/technology/campaign-social-media.html

Zurcher, A. (2019). Clinton emails - what's it all about?. Retrieved from https://www.bbc.com/news/world-us-canada31806907 